\title{
TREATMENT OF RIGIDITY OF THE OS UTEIRI.
}

[Communicated for the Boston Med. and Surg. Journal.]

I READ an interesting article in your Journal of May 15th, relating to the use of lobelia and antirnony in rigidity of the os uteri and perinexurn. It occurred to me that the doses ivere truly "heroic." For the past eight years, I have used, principally, two agents for accomplishing the same object, vir., opium and antimony, with entire suceess, where the os uteri was rigid or not dilatable, after waiting a reasonable time, and preceded by a cup of strong catnip tea, repeated a few times at intervals of half an hour.

'I'he manner of using the antimony is as follows : R. Ant. tart., one half a grain; water, one ounce; mix. Give a teaspoonful every fifteen minutes until nausea occurs, or sweating, or relaxalion of the os. Usually all these events follow in rapid succession, after using from three to five doses. In robust subjects, the antimony is preferred; otherwise the opium in some of its forms, though the latter is not so speedy in its action.

Perhaps in obstinate cases, like those in the article referred to, this treatment might not avail. But so long as half a grain of antimony answers my purpose, and four and a half grains can be saved, I shall probably continue my present plan, reserving heroic treat. ment for formidable cases.

West Medway, Mass., May 27th, 1856. lra Perry.

\section{OPHTHALMIA IN THE BUPFAIO ALASS-HOUSE.}

BY JAMES B. Col.egRove, M.D., BUFFal.o, N. Y.

[Communicated for tho Boston Modical and Surgical Jourual.]

No disease is, or ever has been, so continually present in our County Alms-Honse, as ophthalmia. During the year ending Oet. 1, 1855, I had recorded 121 cases. It was mostly confined to children, of whom there were from 80 to 90 in the Asylum. Out of the whole number of cases, not more than thirty occurred in adults. It was generally either chronic or purulent. 'I'he first was specific inflamination of the sclerotica, which, although very severe, seldom, if ever, degenerated into the purulent. 'The second, by far the severest, most painful, and calanitous, was nevertheless the least obdurate, of easier treatment, and of less duration, than the first.

A few cases of gonorrhceal ophthalmia were admitted during the year. 'This form of the disease, so far as my observation goes, differs only from purulent ophthalmia in the degree of its severity. Cases contracted from this form, do not differ in the slightest from the ordinary purulent or Egyptian ophthalmia.

I believe that in nearly all large charity institutions, where children are congregated together, this malady is likely to occur. It has never been permanently eradicated from the Buffalo Alms-House, 
and I do not believe it ever can be. In fact, the largest part of the children admilted there, are those whose habits and modes of life, previous to their entrance, are such as to predispose them in an emi. nent degree to the ravages of that disease.

On the 1st October, 1854, when I assumed the position of House lhysician, there were 30 cases under treatment, all confined 10 infants and children under 12 years of age. During the summer previous, cholera had swept away nearly a hundred victims, and less altention had been paid to the ophthalmic patients than otherwise would have been. 'These 30 cases were scallered over the entire building. Twelve of them were affected with other diseasesmeasles, or scabies, or both. I immediately resolved upon an entire work of renovation, to accomplish which I required two things: 1, Faithful nursing; 2, Improved diet. 'I'be ophthalmic patients were separated from those having other diseases. A finiblul matron was employed to take care of them. All children having ophthalmia were placed in a large ward together, and all comnection with other children was peremptorily forbidden. 'I'he diet of the children was inproved by the free usc of vegetables. By these means, and the medical treatment which they received, the number of patients was reduced to five on the 1st day of February; and on the 1st of July following, there was not a case in the house-an event which had not occurred before since the construction of the alinshouse. Subsequently the disease was confined mostly to the new cases which were adinitted from the city.

Before alluding particularly to the plan of treatment pursued, I wish to introduce the history of a single case, which was of the grcatest interest to me, as exhibiting the result of purulent ophthalmia when left to take its own course without any treatment whatever.

On the 20th of October, I was myself seized with measles, and obliged, therefore, to keep my bed for the space of twenty days. It was during my illness that Mary Beringer, a German woman, aged 30, contracted purulent ophthalmia, fron sleeping with an Irish woman, who had been admitted with gonorrhoul ophthalmia a day or two previous to my attack. By mistake, she was not seen more than once or twice by a physician during iny illness. 'The disease was consequently left to take its own course, without restraint. At the end of twenty days, the condition of the two eyes was as follows: Right eye.-It appears that while the inflamination was at its height, or during its active stage, the cornca burst, so that the aqueous humor escaped. Now the iris protrudes, and its rough, ragged edges are searcely covered by the lids when the eye is closed. It is in a hopeless condition. Left eyp.-I'the cornea is white and opaque; it has nearly the natural appearance of the sclerotica. It is needless to add, that the poor woman is hopelessly blind.

In the main, the plan of treatment which I adopted was as follows. When it was discovered that the patient was about to be, or 
was already, affected with purulent ophthalmia, a pill of blue mass, from four to ten grains, according to the age of the patient, was administered. If the purulent discharge had commenced, direct application of the stick of nitrate of silver was made to the external surface of the upper and lower lids. The application was thorough, and in nine cases out of ten this treatment was followed by an improvement in the condition of the eyes. 'The diet was confined to farina or mucilage of arrow root, or weak rice soup.

Dr. Watson, 1 believe, mentions blood-letting as the first remedy to be resorted to. I confess I cannot appreciate the value of this remedy, for I have never made use of it ; I mean general blood-letting. In chronic ophthalmia, when the inflammation was coufined to the sclerotica, with no puriform discharge, I have often used local depletion with very decided benefit. The reasons for this are obvious-the condition and habits of the patients forbade thorough resort to the lancet. More was accomplished by the application of powerful astringents, and low diet, than by any other mode of treatment.

Collyria.-I used arg. nitras, acet. plumbi, sulphate zinc, \&c. \&c. I prefer the nitrate of silver.

I have made these general remarks as applicalle to a large number of cases, and do not propose to go into details of any particular casse. I unnex a tabulics statement, which may be of some interest to your readers.

\begin{tabular}{|c|c|c|c|c|c|c|c|}
\hline Age. & lufauts. & 365 & 5 to 3 & 8 to 10 & $10+012$ & Arlults. & Total. \\
\hline $\begin{array}{l}\text { Both eyes lost, } \\
\text { One eye lost, } \\
\text { Ulcerated cornen, } \\
\text { Opacily of cornea, } \\
\text { Vision perfect. }\end{array}$ & $\begin{array}{r}3 \\
1 \\
18\end{array}$ & $\begin{array}{l}\mathbf{3} \\
\mathbf{j} \\
\mathbf{y}\end{array}$ & $\begin{array}{c}2^{*} \\
1^{*} \\
5 \\
8 \\
21\end{array}$ & $\begin{array}{r}3 \\
4 \\
11\end{array}$ & $\begin{array}{r}2 \\
1 \\
19\end{array}$ & $\begin{array}{l}\text { lt } \\
\text { it } \\
1 \\
1\end{array}$ & $\begin{array}{l}3 \\
2 \\
21 \\
16 \\
79\end{array}$ \\
\hline 'otal, & $2 \%$ & 18 & 37 & 18 & 22 & 4 & 121 \\
\hline
\end{tabular}

* 'I'reated all Hospital of the Sisters of Charity. All ophilualmic patients were removed to the Hnspital at the time of the destruction of the Alins-House by fire.

+ This rase received no trealment.

$\ddagger$ This was a cast of gonorriveal ophthalmia.

Antidote to Strychnia.-M. Guibonst lately stated to the Academy of Medicine, that having observed a dog in violent convulsions, in consequence of eating one of the componud balls containing strychnia, he forcibly made it swallow powdered gall-nuts, when the convulsions ceased immediately. Ipecacuanha was then given to the animal, but the latter could not vomit. 'Ihe next day milk was given to it and manna, after which the dog recovered. M. Caventon said that the infusion of galls was a very effectual opponent to vomiting, and hliat he had observed it destroy the power of tartar emetic. M. Orfila had already advised the administration of this infusion, in cases of poisoning by opiun and salts of morphia.Bulletin Univers. 